www.volsu.ru

DOI: https://doi.org/10.15688/jvolsu11.2018.2.6

UDC 664:641.3

LBC L80-106

\title{
QUALITY MANAGEMENT ENRICHING FOOD SYSTEMS FROM DOMESTIC RAW MATERIALS
}

\author{
Tatyana V. Alekseeva
}

Voronezh State University of Engineering Technologies, Voronezh, Russian Federation

\section{Yuliya O. Kalgina}

Voronezh State University of Engineering Technologies, Voronezh, Russian Federation

\section{Dmitry A. Bokarev}

Voronezh State University of Engineering Technologies, Voronezh, Russian Federation

Valeria S. Evlakova

Voronezh State University of Engineering Technologies, Voronezh, Russian Federation

\section{Ludmila A. Malakova}

Voronezh State University of Engineering Technologies, Voronezh, Russian Federation

\section{Evgeniy A. Zdorovtsev}

Voronezh State University of Engineering Technologies, Voronezh, Russian Federation

Abstract. The state policy in Russian Federation in the field of nutrition is aimed at the development of advanced food technologies and the development of food-enriching systems of functional orientation. Rheological properties of model systems with different moisture content on the basis of wheat germ cake as a by-product of flour and oil extraction production were studied. In this paper we investigate a model food system based on wheat wheat germ oil cake of various degrees of hydration with a moisture content in the range of 59-68\%. Rheological properties of food systems were controlled with the help of informationmeasuring system including the device "structure Meter ST-2". Calculation of normal stress showed that with the increase in the mass of water in food systems in the extrusion mass through a die, the mechanical stresses were reduced.

Key words: wheat germ cake, food enrichment systems, normal mechanical stresses.

УДК 664:641.3

ББК Л $80-106$

\section{УПРАВЛЕНИЕ КАЧЕСТВОМ ПИЩЕВЫХ ОБОГАЩАЮЩИХ СИСТЕМ} ИЗ ОТЕЧЕСТВЕННОГО СЫРЬЯ

Татьяна Васильевна Алексеева

Воронежский государственный университет инженерных технологий, г. Воронеж, Российская Федерация

\section{Юлия Олеговна Калгина}

Воронежский государственный университет инженерных технологий, г. Воронеж, Российская Федерация

\section{Дмитрий Александрович Бокарев}

Воронежский государственный университет инженерных технологий, г. Воронеж, Российская Федерация 


\section{Валерия Сергеевна Евлакова}

Воронежский государственный университет инженерных технологий, г. Воронеж, Российская Федерация

\section{Людмила Андреевна Малакова}

Воронежский государственный университет инженерных технологий, г. Воронеж, Российская Федерация

\section{Евгений Анатольевич Здоровцев}

Воронежский государственный университет инженерных технологий, г. Воронеж, Российская Федерация

Аннотация. Государственная политика РФ в области питания населения направлена на развитие перспективных пищевых технологий и разработку пищевых обогащающих систем функциональной направленности. Изучались реологические свойства модельных систем с различным влагосодержанием на основе жмыха зародышей пшеницы как побочного продукта мукомольного и маслоэкстракционного производства. В работе исследовались модельные пищевые системы на основе жмыха зародышей пшеницы различной степени гидратации с влагосодержанием в интервале 59-68 \%. Реологические свойства пищевых систем контролировали с помощью информационно-измерительной системы, включающей в свой состав прибор «Структурометр СТ-2». Расчет нормальных механических напряжений показал, что с увеличением массы воды в пищевых системах при выдавливании их массы через фильеру, механические напряжения уменьшаются.

Ключевые слова: жмых зародышей пшеницы, пищевые обогащающие системы, нормальные механические напряжения.

В настоящее время государственная политика РФ в области питания населения направлена на развитие пищевых технологий, применяющих отечественное сырье глубокой переработки сельскохозяйственной отрасли страны на принципах безотходного производства, рационального использования вторичных продуктов, снижения отходов пищевой промышленности [3; 4; 6].

В этом аспекте побочный продукт мукомольного и маслоэкстракционного производств, жмых зародышей пшеницы (ЖЗП) природный источник ПНЖК, витаминов, макро- и микроэлементов особенно перспективен в разработке пищевых обогащающих систем функциональной направленности.

В любой отрасли производства, пищевая промышленность не является исключением, для достоверности прогнозирования потребительских свойств готовой продукции следует основываться на информации по закономерностям изменения характеристик применяемого сырья. Традиционными критериями в пищевых технологиях являются функционально-технологические свойства сырья, характеризующие его поведение при переработке, а также способность обеспечивать требуемые показатели качества готовых продуктов: структуру, пищевую и биологическую ценность, органолептические показатели. В данном сообщении мы изучали реологические свойства модельных систем с различным влагосодержанием на основе жмыха зародышей пшеницы.

В работе исследовались модельные пищевые системы на основе ЖЗП различной степени гидратации с влагосодержанием в интервале 59-68 \%. Реологические свойства пищевых систем контролировали с помощью информационно-измерительной системы, включающей в свой состав прибор «Структурометр СТ-2» (ФГБНУ НИИ Хлебопекарной промышленности, г. Москва). При работе пищевыми системами применяли два варианта. В первом варианте образец помещали в стакан, который устанавливали на столик прибора под индентором. После касания поршнем пищевой массы происходило ее уплотнение, а затем - выдавливание через фильеру. Сигнал при изменении усилий нагружения на поршне при выдавливании пищевых систем обрабатывался и передавался на информационно-измерительную систему. Во втором варианте применяли измерительное устройство типа пресса, состоящего из неподвижной пластины-основания и подвижной пластины-пуансона. Пуансон связан с информационно-измерительной системой, которая обеспечивает одновременное измерение перемещения и возникшего усилия на пуансоне. В результате обработки данных инфор- 
мационно-измерительной системой получали кривые сжатия [1].

В результате исследований установлено, что гидратированная система с влагосодержанием 59-62 \% по прошествии времени достижения равновесного состояния, имела жесткую, комкообразную, не пластичную структуру, поэтому в дальнейших исследованиях эти соотношения не рассматривались.

С увеличением содержания воды в интервале 64-66 \% (соотношения ЖЗП и воды 1,0:1,7-1,8) структура пищевых систем становилась более мягкой и пластичной, усилия нагружения при выдавливании модельных систем уменьшались и находились в пределах 6-8 Н. Консистенция пищевых систем с влагосодержанием 64-66 \% при набухании компонентов систем в воде и достижении равновесного состояния (5-10 мин) была вязко-текучей, близкой к консистенции мясного фарша или густого теста.

Начиная с влагосодержания модельных систем 68 \% и более их масса приобретала консистенцию жидкого теста, усилия нагружения снижались до значений 4 Н и меньше. Около 1-2 \% воды не связывалось высокомолекулярными веществами ЖЗП и находилось в свободном состоянии в виде надосадочной жидкости. Дальнейшее внесение воды в ЖЗП до соотношений 1,0:8,0 приводило к увеличению количества надосадочной жидкости до 50-70 \% от массы смеси.

Расчет нормальных механических напряжений показал, что с увеличением массы воды в пищевых системах при выдавливании их массы через фильеру, механические напряжения уменьшаются. Изменение нормального механического напряжения при выдавливании массы пищевых систем различной степени гидратации представлено в таблице.
Из таблицы следует, что рациональной влажностью систем является влажность, равная 63-66 \%, что соответствует соотношению сухих веществ и воды - 1,0:1,7-1,8 и консистенции, оцениваемой по нормальному напряжению-2,65-3,27 кПа.

При увеличении количества воды в смеси (соотношение ЖЗП и воды 1,0:1,9 и выше), консистенция пасты из ЖЗП становилась более текучей, что подтверждается низким значением возникающих механических напряжений, в пределах 1,63 кПа и менее. При уменьшении воды в смеси (влагосодержание 59$62 \%$, соотношение ЖЗП и воды 1,0:1,5-1,6), масса имела более плотную и жесткую структуру, что заметно по увеличению механических напряжений (4,49-5,84 кПа).

Таким образом, установлено, рациональное соотношение пищевой обогащающей системы и воды: 1,0:1,7-1,8 (влажность 6466 \%), которое характеризуется нормальными механическими напряжениями в диапазоне 3,27-2,65 кПа, что соответствует аналогичным показателям традиционных многокомпонентных систем из животного и растительного сырья, в состав которых ее целесообразно вводить [2; 5].

\section{СПИСОК ЛИТЕРАТУРЫ}

1. Алексеева, Т.В. Исследование реологических свойств пасты на основе жмыха зародышей пшеницы как компонента пищевых систем из животного сырья / Т. В. Алексеева, Ю. О. Калгина, А. А. Родионов // Известия ВУЗов. Прикладная химия и биотехнология. -2016 . - Т. 6, № 4. С. 133-138.

2. Алексеева, Т. В. Перспективы производства пищевой продукции функциональной направленности с фракциями глубокой переработки отече-

\section{Значения нормальных механических напряжений модельных пищевых систем на основе жмыха зародышей пшеницы}

\begin{tabular}{|c|c|c|}
\hline Влажность пищевых систем, \% & $\begin{array}{c}\text { Соотношение количества жмыха } \\
\text { зародышей пшеницы и воды }\end{array}$ & $\begin{array}{c}\text { Нормальное механическое } \\
\text { напряжение, кПа }\end{array}$ \\
\hline 59,41 & $1,0: 1,5$ & 5,84 \\
\hline 61,55 & $1,0: 1,6$ & 4,49 \\
\hline 63,69 & $1,0: 1,7$ & 3,27 \\
\hline 65,80 & $1,0: 1,8$ & 2,65 \\
\hline 67,91 & $1,0: 1,9$ & 1,63 \\
\hline
\end{tabular}


ственного низкомасличного сырья / Т. В. Алексеева, Ю. О. Калгина, В. Б. Науменко // Технологии пищевой и перерабатывающей промышленности АПК - продукты здорового питания. - 2016. № 4 (12). - С. 58-62.

3. Алехина, Н. Н. Расширение сырьевой базы для производства продуктов питания / Н. Н. Алехина, Е. И. Пономарева, Х. Ю. Боташева // Технологии и оборудование химической, биотехнологической и пищевой промышленности: материалы IX Всероссийской научно-практической конференции студентов, аспирантов и молодых ученых с международным участием. - Барнаул, 2016. - С. 499-501.

4. Белокурова, Е. В. Разработка технологии мучных изделий повышенной пищевой ценности для предприятий общественного питания / Е. В. Белокурова, Я. П. Коломникова, С. А. Солохин // Хлебопродукты. - 2015. - № 1. - С. 56-58.

5. Перспективы введения в меню предприятий HORECA мясорастительных блюд с включением отечественного низкомасличного сырья / Н. С. Родионова, Т. В. Алексеева, Е. С. Попов, Ю. О. Калгина // Товаровед продовольственных товаров. - 2016. - № 4. С. $35-41$.

6. Попов, Е. С. Оценка перспектив сбалансированных по полиненасыщенным жирным кислотам продуктов из отечественного растительного сырья / Е. С. Попов, Н. С. Родионова, О. А. Соколова // Гигиена и санитария. - 2016. - Т. 95, № 1. C. $79-84$.

\section{Information about the Authors}

Tatyana V. Alekseeva, Professor, Department of Service and Restaurant Business, Voronezh State University of Engineering Technologies, Revolutsii Av. 19, 394000 Voronezh, Russian Federation, zyablova@mail.ru.

Yuliya O. Kalgina, Post graduate, Department of Service and Restaurant Business, Voronezh State University of Engineering Technologies, Revolutsii Av. 19, 394000 Voronezh, Russian Federation, Yoliya93@mail.ru.

Dmitry A. Bokarev, Associate professor, Department of Service and Restaurant Business, Voronezh State University of Engineering Technologies, Revolutsii Av. 19, 394000 Voronezh, Russian Federation, zyablova@mail.ru.

Valeria S. Evlakova, Bachelor, Department of Service and Restaurant Business, Voronezh State University of Engineering Technologies, Revolutsii Av. 19, 394000 Voronezh, Russian Federation, lera_evlakova_98@mail.ru.

Ludmila A. Malakova, Bachelor, Department of Service and Restaurant Business, Voronezh State University of Engineering Technologies, Revolutsii Av. 19, 394000 Voronezh, Russian Federation, Mila_1999@mail.ru.

Evgeniy A. Zdorovtsev, Bachelor, Department of Service and Restaurant Business, Voronezh State University of Engineering Technologies, Revolutsii Av. 19, 394000 Voronezh, Russian Federation, Zenya_zvezda@yandex.ru.

\section{Информация об авторах}

Татьяна Васильевна Алексеева, профессор кафедры сервиса и ресторанного бизнеса, Воронежский государственный университет инженерных технологий, просп. Революции, 19, 394000 г. Воронеж, Российская Федерация, zyablova@mail.ru.

Юлия Олеговна Калгина, аспирант кафедры сервиса и ресторанного бизнеса, Воронежский государственный университет инженерных технологий, просп. Революции, 19, 394000 г. Воронеж, Российская Федерация, Yoliya93@mail.ru.

Дмитрий Александрович Бокарев, доцент кафедры сервиса и ресторанного бизнеса, Воронежский государственный университет инженерных технологий, просп. Революции, 19, 394000 г. Воронеж, Российская Федерация, zyablova@mail.ru.

Валерия Сергеевна Евлакова, бакалавр кафедры сервиса и ресторанного бизнеса, Воронежский государственный университет инженерных технологий, просп. Революции, 19, 394000 г. Воронеж, Российская Федерация, lera_evlakova_98@mail.ru. 
Людмила Андреевна Малакова, бакалавр кафедры сервиса и ресторанного бизнеса, Воронежский государственный университет инженерных технологий, просп. Революции, 19, 394000 г. Воронеж, Российская Федерация, Mila_1999@mail.ru.

Евгений Анатольевич Здоровцев, бакалавр кафедры сервиса и ресторанного бизнеса, Воронежский государственный университет инженерных технологий, просп. Революции, 19, 394000 г. Воронеж, Российская Федерация, Zenya_zvezda@yandex.ru. 